\title{
Multi-Criteria Decision Making Semantic for Mental Healthcare
}

\author{
Chaymae Benfares, System Engineering Laboratory, Ibn Tofail University, Morocco \\ iD https://orcid.org/0000-0003-3921-0681 \\ Ouidad Akhrif, System Engineerin Laboratory, Ibn Tofail University, Morocco \\ Younès El Bouzekri El Idrissi, System Engineering Laboratory, Ibn Tofail University, Morocco \\ Karim Hamid, Center for Oncology and Hematology, Morocco
}

\begin{abstract}
Healthcare systems play an important role in the well-being of patients; however, the diagnostic process generates a very large and varied types of data which makes the process of analyzing this data very complicated. More precisely, depression, which is one of the most common psychological disorders, contains a taxonomy of different symptoms, heterogeneous, and varied by data criteria, as confronted by clinicians to predict the degree of the disorder in patients with the aim of selecting the best treatment. To this end, the authors propose a decision architecture based on an approach that combines method ontologies, the Analytic Hierarchy Process, in the context of the prevention and monitoring of depression trends in patients.
\end{abstract}

\section{KEYWORDS}

AHP, Analytic Hierarchy Process, Decision-Making, Mental Health Care, Multi-Criteria, Ontology

\section{INTRODUCTION}

In the health sector, the volume of data collected for each patient is very varied and important ; however, clinicians usually face problems with analyzing this data and extracting the criteria relevant for a diagnosis. On the one hand, and more specifically, in the field of mental health, depression is one of the main causes of mental illness (American Psychiatric Association, 2015); indeed, it is one of the most common psychological disorders. In fact, the World Health Organization (WHO) (2018) predicts that depression will become the main cause of mental illness in the next 15 years. According to WHO, depression is one of the priority pathologies targeted by the Mental Health Gap Action Program (mhGAP) (WHO, 2018). The purpose of this program is to help countries expand services for people with mental disorders. On the other hand, at public health institutions, like the University Hospital Center Mohammed VI in Marrakech "(CHU)," cancer patients require permanent support and follow up during their oncology care, because they face major constraints while suffering and undergoing treatment, and other psychopathological reactions and symptoms that are identical to depression. Indeed the problem is defined: how can clinicians decide and select in a solid and automatic way the symptoms of depression, compared to other psychopathological reactions of the cancer disease? Due to the large number of patients, it is difficult to consider all these parameters to develop a relevant prevention system. In addition, the constraint of missing, unstructured, and noisy data adds more challenges ; therefore, the selection of relevant and personalized criteria (symptoms) 
for each patient remains an arduous task. Indeed, the major challenge facing clinicians is the problem of analysis of knowledge at the patient level. Moreover, to the multitude of diagnostic protocols, because they are diverse criteria, therefore the degree of uncertainty among clinicians increases.

In recent years, decision-making in medicine has taken a very important place in the science of medical informatics; indeed many approaches and methods stemming from Artificial Intelligence, assistance systems to decision-making, and mathematical modeling techniques, are gradually being introduced into mental health (Brunelli, 2014), in order to help decision-makers and health professionals make informed decisions based on solid foundations (Aoki, Uehara, Kato, \& Hirahara, 2016). It is in this context we adopted the multi-criteria decision method of the Analytic Hierarchy Process (AHP), which is an analytical approach to support decision-making according to a multicriteria approach. Developed by Thomas Saaty, it is basically based on complex calculations (Aoki et al., 2016), in order to extract the relevant diagnostic criteria. In addition, we proposed a hierarchical ontological model based on domain ontology, in order to exploit the preferences of each user (extracted by the diagnostic sheet and the test), and to be able to promote the integration of heterogeneous knowledge. The ontologies represent a very reliable and structured source of knowledge, and are robust means to represent and exploit the data and the knowledge of a field, and, more particularly, that of the medical field. Our case study is the modeling of the pathologies of depression based on the opinions of clinical experts and the DSM (American Psychiatric Association, 2015). In this context, this paper presents the intelligent decision framework to automatically monitor and predict the level of depression in cancer patients, so that clinicians can make the best decision to ensure better patient monitoring and reduce the impact of their suffering from the disease on their psychology.

This document is organized as follows: Section 2 describes some related work; Section 3 describes the methods used in this study. In Section 4, we present in detail the proposed system, the experimentation, and the results obtained.

\section{RELATED WORK}

In a world whose complexity is rapidly growing, making the best decisions becomes an increasingly demanding task (Brunelli, 2014). Indeed, optimal and relevant decision-making is a difficult task in all areas, especially in the health field. Physicians face several challenges ; however, many intelligent methods from artificial intelligence, applied mathematics, and operational research is useful for helping decision makers make relevant decisions.

The ontologies are widely used in medical informatics and health care to standardize the vocabulary and share knowledge on a particular domain.

Therefore, in recent years, many researchers have proposed work and research in the field of health, especially mental health, to help doctors make the most relevant and accurate decision. For example, a recent study described a new approach for diagnosing anxiety and depression in young children (Mcginnis et al., 2018). Furthermore Aoki, Uehara, Kato, and Hirahara (2016) presented a study that sought to develop an evaluation index of rugby players' psychological competitive ability as their mental aspects. Moreover, other authors treat the noises depression based on statistic analysis algorithm for kerma area product meter design (Hsieh \& Chen, 2018).

Besides, in recent years, much research has been based on systems of decision support, using the Analytic Hierarchy Process (AHP). On the one hand, Ran's (2011) paper applied the AHP for evaluating the energy-indicators system for sustainable development. On the other hand, Ouyang's (2017) paper presented an adaptive, vertical handover algorithm based on the Fuzzy Analytic Hierarchy Process (FAHP). And Hong and Yongsai's (2017) paper put forward a method for evaluating the rescue-priority level of power lines post-disaster based on the AHP. Jaglarz's (2018) study presented the bathroom as a place for health care by applying intelligent technology systems, including Internet of Things (IoT) technologies, in a bathroom space, and Carroll, Richardson, Moloney, Reilly, and 
Carroll (2017) described how to bridge health care education and technology solution development through experiential innovation.

This paper presents the intelligent decision framework for automatically predicting the level of depression in cancer patients. The added value of this work relies on the selection, in a robust and automatic way, the symptoms of depression, compared to other psychopathological reactions of cancer disease. It is based on the multi-criteria, decision-making AHP approach, so that clinicians can select the best decision, to ensure a better follow up of patients.

\section{SYSTEM OVERVIEW}

A medical-decision support system is an organized set of information, designed to assist the practitioner in his reasoning, with a view to identifying a diagnosis and choosing the appropriate therapy, by operating a dialogue between man and machine (Cléret, Le Beux, \& Le Duff, 2001). However, the situation becomes complex when the decision maker faces choosing the best decision that best fits the patient context based on several criteria and alternatives.

On the other hand, in practice in public health-more specifically in oncology-clinicians and psycho-oncology practitioners face a constraint of automatically and rigorously distinguishing between the symptoms of depression and psychopathological symptoms that are identical to depression (which are reactions in the normal process of adaptation to cancerous disease). In this regard, this paper presents a decision support system. We opted for the AHP approach to help clinicians choose the best decision regarding the level of depression in order to ensure ubiquitous follow up of patients. We used the domain ontology in our case study, in order to standardize the vocabulary of the system and in order to improve and respond to the problems of heterogeneity and personalization of a diagnosis, adapted to the patient's symptoms.

Figure 1 presents the proposed system steps for the purpose; we try to answer the problems encountered in practice within the "(CHU)" oncology and hematology center. On the one hand, regarding the data, the alternatives, and the criteria, we processed relevant data from the CHU diagnostic card to extract the main diagnostic criteria (we will detail them in Section 5); on the other hand, we used the AHP approach to choose the best alternative.

In this present work, we propose the architecture of the system, which is divided into three main steps:

Step 1: The collection of diagnostic criteria (symptoms) from a diagnostic CHU sheet.

Step 2: The representation of knowledge based on domain ontology.

Step 3: The treatment of symptoms based on the analytical approach AHP multiple criteria.

Step 4: Decision-making based on evaluation alternatives.

\section{THEORETICAL BACKGROUND}

\section{Introduction to Analytic Hierarchy}

At first, decision-making can be defined as a series of cognitive processes including evaluation, comparison, reasoning, and selection of possible alternatives (Jaglarz, 2018), based on relevant information, and optimized by maximizing utility Marwala (2014). Moreover, the AHP is a decisionsupport model developed by Thomas L. Saaty of the University of Pittsburgh (Hong \& Yongsai, 2017), which supports decision-making with a multi-criteria approach. The selection of a solution among alternatives, according to a certain number of criteria, when the decision maker has many evaluation criteria (Ran, 2011), is fundamentally based on complex calculations.

This method has been used in several areas, such as transport planning, energy rationing, risk management projects, comparative analysis of logistics operations, and quality management of services 


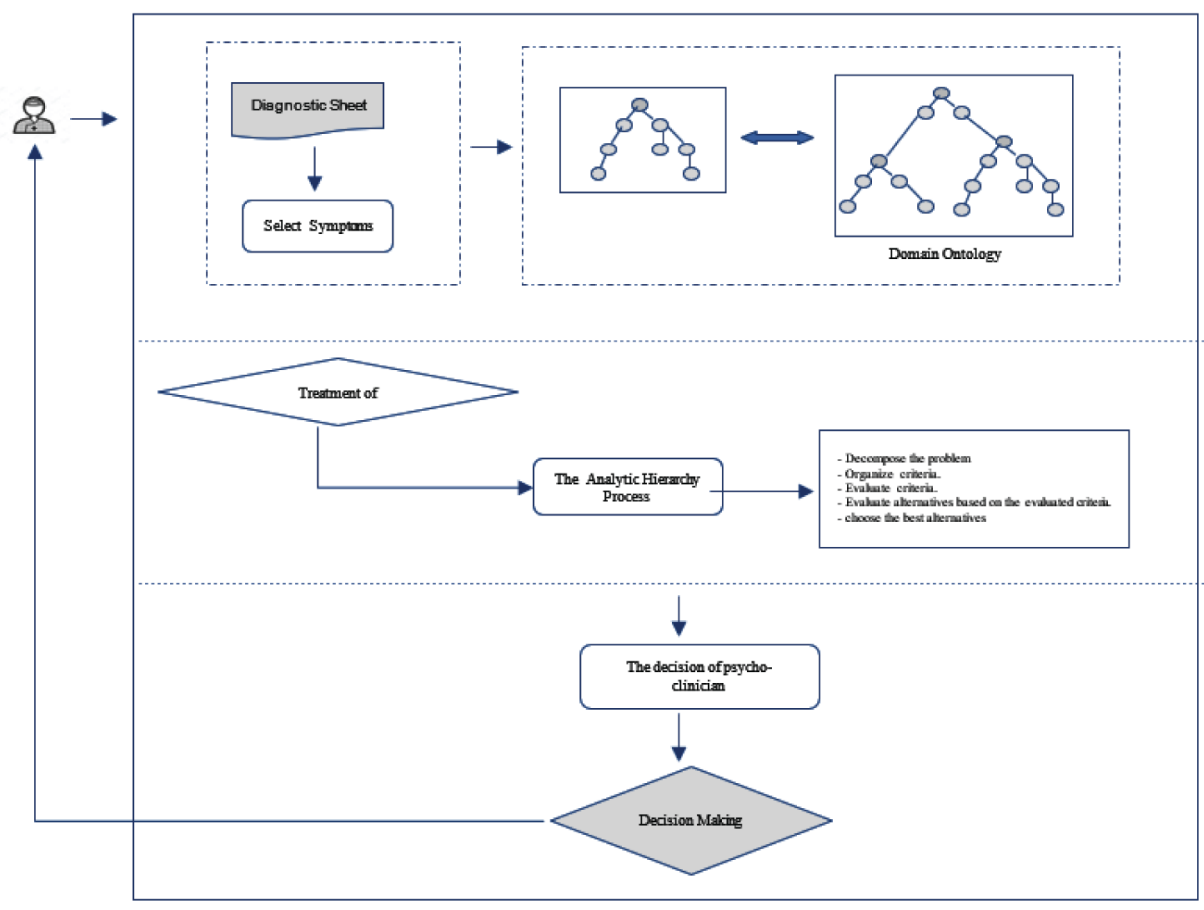

in hospitals, allowing users to decompose a complex problem in a hierarchical system (Brunelli, 2014). The hierarchical ranking of alternatives and criteria is defined by the decision maker.

The execution of the AHP method is based on the following main steps (Brunelli, 2014; Saaty, 1980):

1. Decompose down the problem by building a next hierarchy (see Figure 2). Determine the goal, criteria, and alternatives;

2. Define the weight of each criterion according to its priority, based on the Saaty scale (Saaty, 1980) (see Table 1), comparing in pairs each criterion; the second comparison is between the alternatives with respect to each criterion. Table 1 shows the different weights of the Saaty scale and their linguistic significance;

3. Determine an overall ranking of the alternatives related to the main objective of the decision, by calculating the weight of each alternative in relation to the criteria.

We present, in the following section, the experimental study of the AHP approach in our decision framework, related to the decision of degree of depression in cancer patients, in the oncology and hematology center of the University Hospital of Marrakech.

\section{Ontology}

Ontology is a central concept of the semantic Web (Benfares, Idrissi, \& Hamid, 2019). An ontology formally defines a common set of terms and concepts that are used to describe and represent a domain. An ontology is domain specific and is used to describe and represent an area of knowledge. There is another level of relationship expressed using a special group of terms: properties. An ontology is 


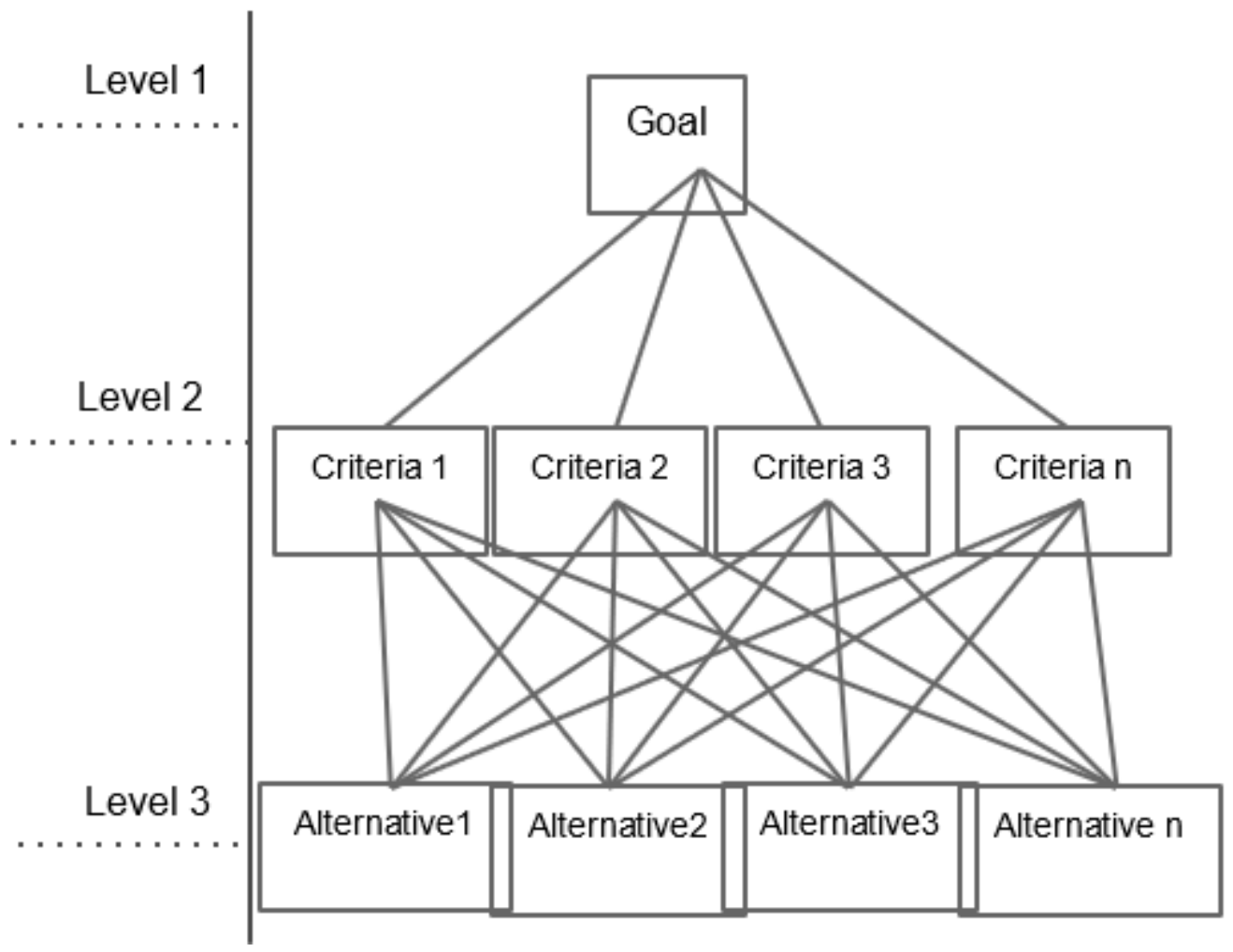

Table 1. Linguistic variable scales

\begin{tabular}{|l|l|}
\hline Saaty's Scale & \multicolumn{1}{c|}{ Linguistic Meaning } \\
\hline 1 & Equal important \\
\hline 3 & Moderately more important \\
\hline 5 & Strongly more important \\
\hline 7 & Very strongly important \\
\hline 9 & Extremely more important \\
\hline $2,4,6,8$ & Intermediate values of importance \\
\hline Inverse & If, for activity “i” gets one number over activity “ $\mathrm{j}$, " then " $\mathrm{j}$ " has its opposite value than " $\mathrm{i}$ " \\
\hline
\end{tabular}

a representation of general properties of what exists in a formalism allowing automatic processing Kouame, A. (2018).

A domain ontology describes the terminology and relationships between terms in a specific domain. The ontologies can be written in different programming languages, to provide a formal description of concepts, terms, or relationships of any domain (Benfares et al., 2019). These languages are RDFS (Resource Description Framework Schema) and OWL (Web Ontology Language) (Benfares, Bouzekri, Idrissi, \& Abouabdellah, 2017). 
We used the ontology in our system to normalize the vocabulary of the system in order to improve and respond to the problems of heterogeneity and personalization of a diagnosis adapted to the patient's symptoms.

\section{EXPERIMENTAL STUDY: DECISION-MAKING SEMANTICS FOR DETERMINE THE LEVEL OF DEPRESSION}

In the present work, we present a model for smart decision-making, one side was based on relevant data from the Oncology and Hematology Center Hospital, and on the other side, we opted the AHP approach to help clinicians make a better decision. As we showed in the preceding section (system overview), to determine the criteria and alternatives forthe implementation of the approach in our case study, we used a diagnostic CHU sheet.

\section{Ontology-Based Approach}

In this section, we present the ontology-based case study model. Knowledge modeling and representation is based on domain ontology, with the aim of facilitating and guaranteeing cooperation between clinicians and the diagnostic system. We used the ontology language OWL (Web Ontology Language) (a language used to define and instantiate Web Ontologies), because it allowed us to represent and exploit the knowledge of a domain in a very robust way.

In this work, we used Protégé (an open-source ontology editor and knowledge management system that provides a graphic user interface to define ontologies); we use a simplified ontology of symptoms of depression as shown in Figure 3.

The patient profile contains all the information necessary to design a relevant diagnosis, in order to personalize it. The patient profile contains personal data and the test information.

\section{Decision-Making-Based on the AHP}

In this section we describe all the steps involved in executing the Analytic Hierarchy Process approach in our decision framework as defined in the previous section:

Figure 3. Concept description from an "Ontology model of symptom"

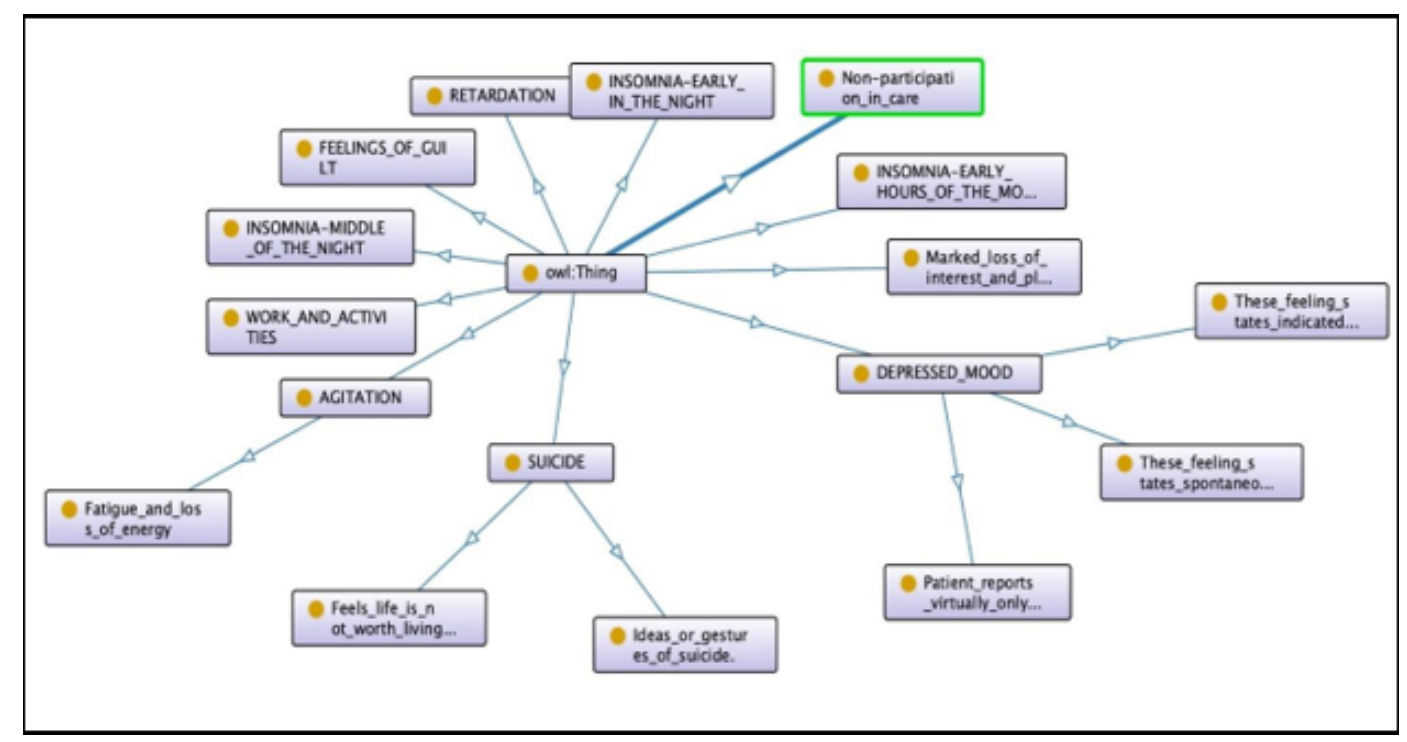


1. Figure 3 presents the problem of hierarchy in our case study on the best alternatives in decisionmaking regarding the degree of depression in cancer patients:

a. The Goal: Predict the degree of depression most appropriate for a certain patient;

b. Criteria: Extract all the relevant criteria, based on the diagnostic sheet; they present the symptoms of depression. Table 2 shows the different criteria used in our case study;

c. Alternative: Present the possible alternatives related to the degree of depression. Table 3 shows all the alternatives used in our case study.

The steps we followed from the AHP method (Brunelli, 2014) are as follows:

Step 1: Decompose the problem and define the hierarchy.

Step 2: Establish the comparison judgment matrices.

Step 3: Determine the priority of each matrix.

Step 4: Calculate the 'Consistency Ratio' of each matrix.

Step 5: Derive 'Consistency' from judgments.

Tables 2 and 3 show the code for each criterion, and each alternative.

\section{Comparisons Between Criteria}

The first comparison matrix (see Table 4) between the criteria and the clinician (expert in psychology) evaluates each criterion based on its importance, using linguistic terms, which are then associated with real numbers; we based these on the scale of Saaty (see Table 1).

\section{Eigenvector Calculation}

After the establishment of the judgment matrices, the crucial step of the AHP is to derive a priority vector (see Table 5) for each pairwise comparison matrix. The most popular method for estimating a priority vector is that proposed by Saaty (Brunelli, 2014).

Table 2. Table code of criteria

\begin{tabular}{|l|l|}
\hline \multicolumn{1}{|c|}{ Criteria } & Code \\
\hline Recurrent thoughts of death/suicide & S 1 \\
\hline Non-participation in care & S 2 \\
\hline Insomnia almost every day & S 3 \\
\hline Fatigue and loss of energy & S 4 \\
\hline Marked loss of interest and pleasure & S 5 \\
\hline
\end{tabular}

Table 3. Table code of alternative

\begin{tabular}{|l|l|}
\hline \multicolumn{1}{|c|}{ Alternative } & \multicolumn{1}{c|}{ Code } \\
\hline Mild depression & A 1 \\
\hline Moderate depression & A 2 \\
\hline Severe-moderate-depression & A 3 \\
\hline Severe depression & A 4 \\
\hline
\end{tabular}


Table 4. Table comparison matrix between criteria

\begin{tabular}{|c|c|c|c|c|c|}
\hline & S1 & S2 & S3 & S4 & S5 \\
\hline S 1 & $\mathbf{1}$ & $1 / 3$ & 2 & 2 & 5 \\
\hline S 2 & 3 & $\mathbf{1}$ & 1 & 3 & 3 \\
\hline S 3 & $1 / 2$ & 1 & $\mathbf{1}$ & 1 & 3 \\
\hline S 4 & $1 / 2$ & $1 / 3$ & $1 / 3$ & $\mathbf{1}$ & $\mathbf{2}$ \\
\hline S 5 & $1 / 5$ & $1 / 3$ & $1 / 3$ & $\mathbf{1}$ \\
\hline
\end{tabular}

\section{Calculate Consistency Ratio}

The consistency ratio (CR), is the rescaled version of consistency index (CI), given a matrix of order n. CR can be obtained by dividing CI by a real number (random index) (Brunelli, 2014):

$C R=\frac{C I}{R I_{n}} ; \mathrm{CI}$ is Consistency Index

$R I_{n} ;$ Random index was developed by Saaty (see Table 6)

The calculation of the value of consistency ratio is more important, to show the coherence of the judgments of the calculated matrix. For this purpose, the value of (CR) must be less than $0.1(10 \%)$ for the matrix to be consistent (Brunelli, 2014).

\section{Calculate Consistency Index}

$\mathrm{CI}$ is obtained from a large enough set of randomly generated matrices of size $\mathrm{n}$. The values estimated for are shown in Table 5. The coherence index is calculated by the equation below:

$$
\begin{aligned}
& C I=\frac{\lambda_{\text {max }}-n}{n-1} \\
& \mathrm{n}=\text { number of criteria }
\end{aligned}
$$

\section{Calculate Eigenvalue $\lambda_{\max }$}

The next step is to calculate the eigenvalue $\lambda_{\max }$ of each matrix. The elements of the vector of the weighted sum are divided by the corresponding priority for each criterion.

\section{Table 5. Table priority between criteria}

\begin{tabular}{|c|c|c|c|c|c|c|}
\hline & S1 & S2 & S3 & S4 & S5 & Priority \\
\hline S1 & 1 & $1 / 3$ & 2 & 2 & 5 & 0.264 \\
\hline S2 & 3 & 1 & 1 & 3 & 3 & 0.337 \\
\hline S3 & $1 / 2$ & 1 & 1 & 2 & 3 & 0.218 \\
\hline S4 & $1 / 2$ & $1 / 3$ & $1 / 3$ & 1 & 2 & 0.107 \\
\hline S5 & $1 / 5$ & $1 / 3$ & $1 / 3$ & $1 / 2$ & 1 & 0.069 \\
\hline
\end{tabular}


Table 6. Random coherence index of Saaty

\begin{tabular}{|c|c|c|c|c|c|c|c|c|}
\hline Number of Criteria & $\mathbf{1}$ & $\mathbf{2}$ & $\mathbf{3}$ & $\mathbf{4}$ & $\mathbf{5}$ & $\mathbf{6}$ & $\mathbf{7}$ & $\mathbf{8}$ \\
\hline$R I_{n}$ & 0 & 0 & 0.58 & 0.90 & 1.12 & 1.24 & 1.32 & 1.41 \\
\hline
\end{tabular}

The $\lambda_{\max }$ value of the comparison matrix between the criteria of our case study is as follows:

$\lambda_{\text {max }}=5.434$

In our case study, the calculation of the consistency of judgment between the criteria is as follows.

The value of the eigenvalue is:

$\lambda_{\max }=5.434$

Consistency Index:

$C I=\frac{\lambda_{\max }-N}{N-1}=\frac{5.434-5}{5-1}=0.108$

$R I_{n}=1.12$

We have five criteria, so:

$C R=\frac{0.108}{1.12}=0.096$

Regarding the consistency ratio, we conclude that the value of $\mathrm{CR}=0.096$, so $\mathrm{CR} \leq 0.1$ or (CR $\leq 10 \%$ ). So the degree of consistency of comparison is consistent (acceptable).

The following section presents the matrices of judgment, comparisons between the alternatives and each criterion, and the results of the priority and the consistency of each comparison matrix.

\section{Comparisons Between Alternatives With Report to Each Criterion}

We established the comparison judgment matrix between the alternatives, with respect to each criterion, by calculating the priority vectors, the coherence index, and the coherence ratio in order to check the consistency of the judgment.

The first comparison matrix between alternatives relative to the symptom 4 criterion is shown in Table 7.

We conclude that the value of $\mathrm{CR}=0.055$, so $\mathrm{CR} \leq 0.1$ or $(\mathrm{CR} \leq 10 \%)$. So the degree of consistency of comparison is consistent (acceptable).

The second matrix presents the comparison between the alternatives versus the symptom 5 (marked loss of interest and pleasure), as shown in Table 8.

We conclude that the value of $\mathrm{CR}=0.056$, so $\mathrm{CR} \leq 0.1$ or $(\mathrm{CR} \leq 10 \%)$. So the degree of consistency of comparison is consistent (acceptable).

The third matrix presents the comparison between the alternatives versus the symptom 2 (nonparticipation in care), as shown in Table 9. 
Table 7. Comparison matrix between alternatives according to symptom 4 (fatigue and loss of energy)

\begin{tabular}{|c|c|c|c|c|c|}
\hline Symptom 4 & $\begin{array}{c}\text { Severe- } \\
\text { Depression }\end{array}$ & $\begin{array}{l}\text { Severe- } \\
\text { Moderate- } \\
\text { Depresion }\end{array}$ & $\begin{array}{l}\text { Moderate- } \\
\text { Depression }\end{array}$ & $\begin{array}{c}\text { Mild } \\
\text { Depression }\end{array}$ & Priority \\
\hline Severe-Depression & 1 & 2 & 2 & 2 & 0.379 \\
\hline Severe-moderate-depression & $1 / 2$ & 1 & 2 & 3 & 0.292 \\
\hline Moderate-depression & $1 / 2$ & $1 / 2$ & 1 & 3 & 0.212 \\
\hline Mild-depression & $1 / 2$ & $1 / 3$ & $1 / 3$ & 1 & 0.114 \\
\hline$\lambda_{\max }=4.15$ & & $R I_{n}=0.90$ & $C R=\frac{C I}{R I_{n}}=$ & $\frac{05}{90}=0.055$ & $\mathrm{CR}=0.055$ \\
\hline
\end{tabular}

Table 8. Comparison matrix between alternatives according to symptom 5 (marked loss of interest and pleasure)

\begin{tabular}{|l|l|l|l|l|l|}
\hline \multicolumn{1}{|c|}{ Symptom 5 } & \multicolumn{1}{|c|}{ Severe-Depression } & $\begin{array}{c}\text { Severe- } \\
\text { Moderate- } \\
\text { Depresion }\end{array}$ & $\begin{array}{c}\text { Moderate- } \\
\text { Depression }\end{array}$ & $\begin{array}{c}\text { Mild } \\
\text { Depression }\end{array}$ & Priority \\
\hline Severe-Depression & 1 & 3 & 4 & 4 & 0.519 \\
\hline $\begin{array}{l}\text { Severe-moderate- } \\
\text { depression }\end{array}$ & $1 / 3$ & 1 & 3 & 2 & 0.240 \\
\hline Moderate-depression & $1 / 4$ & $1 / 3$ & 1 & 2 & 0.135 \\
\hline Mild-depression & $1 / 4$ & $1 / 2$ & $1 / 2$ & 1 & 0.102 \\
\hline$\lambda_{\max }=4.153$ & $C I=\frac{\lambda_{\max }-n}{n-1}=0.051$ & $R I_{n}=0.90$ & $C R=\frac{C I}{R I}=\frac{0.051}{0.90}=0.055$ & $\mathrm{CR}=0.056$ \\
\hline
\end{tabular}

We conclude that the value of $\mathrm{CR}=0.074$, so $\mathrm{CR} \leq 0.1$ or $(\mathrm{CR} \leq 10 \%)$. So the degree of consistency of comparison is consistent (acceptable).

The fourth matrix presents the comparison between the alternatives versus the symptom 3 (insomnia almost every day), as shown in Table 10.

We conclude that the value of $\mathrm{CR}=0.033$, so $\mathrm{CR} \leq 0.1$ or $(\mathrm{CR} \leq 10 \%)$. So the degree of consistency of comparison is consistent (acceptable).

The fifth matrix presents the comparison between the alternatives versus the symptom 1 (recurrent thoughts of death/suicide), as shown in Table 11.

We conclude that the value of $\mathrm{CR}=0.025$, so $\mathrm{CR} \leq 0.1$ or $(\mathrm{CR} \leq 10 \%)$. So the degree of consistency of comparison is consistent (acceptable).

After establishing the criteria comparison matrix and calculating the weights, the last step is to calculate the weight of the alternatives. We used the following formula to determine a global ranking of the alternatives (the final weight for a given alternative is calculated as follows). Therefore, the goal is yielded by the best alternative score (Priority):

$$
S_{i}=\sum_{i=1}^{N} w_{j} \times e_{i j}
$$


Table 9. Comparison matrix between alternatives according to symptom 2 (non-participation in care)

\begin{tabular}{|c|c|c|c|c|c|}
\hline Symptom 2 & Severe-Depression & $\begin{array}{l}\text { Severe- } \\
\text { Moderate- } \\
\text { Depresion }\end{array}$ & $\begin{array}{l}\text { Moderate- } \\
\text { Depression }\end{array}$ & $\begin{array}{c}\text { Mild } \\
\text { Depression }\end{array}$ & Priority \\
\hline Severe-Depression & 1 & 2 & 3 & 5 & 0.458 \\
\hline $\begin{array}{l}\text { Severe-moderate- } \\
\text { depression }\end{array}$ & $1 / 2$ & 1 & 3 & 3 & 0.29 \\
\hline Moderate-depression & $1 / 3$ & $1 / 3$ & 1 & 4 & 0.174 \\
\hline Mild-depression & $1 / 5$ & $1 / 3$ & $1 / 4$ & 1 & 0.074 \\
\hline$\lambda_{\max }=4.200$ & $C I=\frac{\lambda_{\max }-4}{n-1}=0.066$ & $R I_{n}=0.90$ & $C R=\frac{C I}{R I_{n}}=$ & $\frac{.066}{.90}=0.074$ & $\begin{array}{l}\mathrm{CR}= \\
0.074\end{array}$ \\
\hline
\end{tabular}

Table 10. Comparison matrix between alternatives according to symptom 3 (insomnia almost every day)

\begin{tabular}{|c|c|c|c|c|c|}
\hline Symptom 3 & Severe-Depression & $\begin{array}{l}\text { Severe- } \\
\text { Moderate- } \\
\text { Depresion }\end{array}$ & $\begin{array}{l}\text { Moderate- } \\
\text { Depression }\end{array}$ & $\begin{array}{c}\text { Mild } \\
\text { Depression }\end{array}$ & Priority \\
\hline Severe-Depression & 1 & 1 & 3 & 2 & 0.331 \\
\hline $\begin{array}{l}\text { Severe-moderate- } \\
\text { depression }\end{array}$ & 1 & 1 & 4 & 5 & 0.429 \\
\hline Moderate-depression & $1 / 3$ & $1 / 4$ & 1 & 3 & 0.154 \\
\hline Mild-depression & $1 / 2$ & $1 / 5$ & $1 / 3$ & 1 & 0.083 \\
\hline$\lambda_{\max }=4.09$ & $C I=\frac{\lambda_{\max }-4}{n-1}=0.03$ & $R I_{n}=0.90$ & \multicolumn{2}{|c|}{$C R=\frac{C I}{R I_{n}}=0.0333$} & $\mathrm{CR}=0.033$ \\
\hline
\end{tabular}

Table 11. Comparison matrix between alternatives according to symptom 1 (recurrent thoughts of death/suicide)

\begin{tabular}{|c|c|c|c|c|c|}
\hline Symptom 1 & Severe-Depression & $\begin{array}{l}\text { Severe- } \\
\text { Moderate- } \\
\text { Depresion }\end{array}$ & $\begin{array}{l}\text { Moderate- } \\
\text { Depression }\end{array}$ & $\begin{array}{c}\text { Mild } \\
\text { Depression }\end{array}$ & Priority \\
\hline Severe-Depression & 1 & 1 & 5 & 7 & 0.440 \\
\hline $\begin{array}{l}\text { Severe-moderate- } \\
\text { depression }\end{array}$ & 1 & 1 & 3 & 5 & 0.333 \\
\hline Moderate-depression & $1 / 5$ & $1 / 3$ & 1 & 3 & 0.126 \\
\hline Mild-depression & $1 / 7$ & $1 / 5$ & $1 / 3$ & 1 & 0.057 \\
\hline$\lambda_{\max }=4.07$ & $C I=\frac{\lambda_{\max }-4}{n-1}=0.023$ & $R I_{n}=0.90$ & \multicolumn{2}{|c|}{$C R=\frac{C I}{R I_{n}}=0.025$} & $\mathrm{CR}=0.025$ \\
\hline
\end{tabular}


Table 12. Ranking of the alternatives

\begin{tabular}{|l|l|l|l|l|l|}
\hline & \multicolumn{1}{|c|}{$\begin{array}{c}\text { Severe- } \\
\text { Depression }\end{array}$} & $\begin{array}{c}\text { Severe- } \\
\text { Moderate- } \\
\text { Depresion }\end{array}$ & $\begin{array}{c}\text { Moderate- } \\
\text { Depression }\end{array}$ & Mild Depression & Priority \\
\hline Symptom 1 & 0.44 & 0.33 & 0.126 & 0.057 & 0.264 \\
\hline Symptom 2 & 0.458 & 0.29 & 0.174 & 0.074 & 0.218 \\
\hline Symptom 3 & 0.331 & 0.429 & 0.154 & 0.083 & $\mathbf{0 . 3 3 7}$ \\
\hline Symptom 4 & 0.379 & 0.292 & 0.212 & 0.114 & 0.107 \\
\hline Symptom 5 & 0.519 & 0.24 & 0.135 & 0.102 & 0.069 \\
\hline
\end{tabular}

$\mathrm{N}$ is the number of criterion.

In this case study, we have relied on the techniques of the AHP method to provide a solution that exactly fits our problem of uncertainty about the choice of the best and relevant alternative. For this purpose, we have established the problem hierarchy of decision-making on the degree of depression, precisely in patients with "(CHU)" cancer at the Marrakech Oncology and Hematology Center. We applied the AHP multi-criteria analysis method, so that clinicians can make the best decision, in other words, choose the best alternative, to address the problem of distinguishing between the criteria of depression and other psychopathological reactions of cancer. In this study, we have studied five criteria and four alternatives, we have calculated the priority and the consistency ratio for each comparison matrix, and the results have agreed and are consistent, and all the judgments are logical and consistent, since the AHP relies fundamentally on complex calculations (Table 12).

\section{CONCLUSION}

The goal of the health systems is to ensure patients are followed up with in an intelligent way and to improve the diagnostic care to minimize the risks of the patients in terms of follow up and prevention. In this regard, in this work, we proposed a decision support system in the context of the prevention and prediction of the degree of depression in cancer patients in the oncology and hematology center of the University Hospital Center. An analytic hierarchy process analysis was used to evaluate the criteria and alternatives, and we used five criteria in this case study. In addition, we developed an ontology model to represent knowledge in order to capture the symptoms of each patient in a relevant way. The results of the simulation show that the model is weak and has provided satisfactory results.

\section{ACKNOWLEDGMENT}

This work was supported in part by the unit of psychology at the Center of Oncology and Hematology of the University Hospital Mohammed VI Of Marrakech, Morocco. 


\section{REFERENCES}

American Psychiatric Association. (2013). Diagnostic and statistical manual of mental disorders (DSM-5). American Psychiatric Pub.

Aoki, K., Uehara, M., Kato, C., \& Hirahara, H. (2016). Evaluation of Rugby Players' Psychological-Competitive Ability by Utilizing the Analytic Hierarchy Process, Open. J. Soc. Sci., 04(12), 103-117.

Benfares, C., El Bouzekri El Idrissi, Y., \& Abouabdellah, A. (2017, March). Recommendation semantic of services in smart city. In Proceedings of the 2nd international Conference on Big Data, Cloud and Applications (pp. 1-6). Academic Press. doi:10.1145/3090354.3090407

Benfares, C., El Idrissi, Y. E. B., \& Hamid, K. (2018, July). Personalized Healthcare System Based on Ontologies. In Proceedings of the International Conference on Advanced Intelligent Systems for Sustainable Development (pp. 185-196). Springer.

Brunelli, M. (2014). Introduction to the analytic hierarchy process. Springer.

Carroll, N., Richardson, I., Maloney, M., \& O’Reilly, P. (2017). Bridging healthcare education and technology solution development through experiential innovation. Health Technol., 7, 1-7.

Cléret, M., Le Beux, P., \& Le Duff, F. (2001). Medical decision support systems.

Hsieh, C., \& Chen, C. (2018). Noises Depression Based on Statistic Analysis Algorithm for Kerma Area Product Meter Design. In Proceedings of the 2018 IEEE Int. Instrum. Meas. Technol. IEEE Press.

Jaglarz, A. (2018, January). "Intelligent Bathroom"-Intelligent Decision for Health. In Proceedings of the International Conference on Intelligent Human Systems Integration (pp. 125-130). Springer. doi:10.1007/9783-319-73888-8_21

Kouame, A. (2018). Management system of traditional medicine in a social and semantic web platform: an approach based on a visual ontology [Doctoral dissertation].

Marwala, T. (2014). Artificial intelligence techniques for rational decision making. Springer. doi:10.1007/9783-319-11424-8

McGinnis, R. S., McGinnis, E. W., Hruschak, J., Lopez-Duran, N. L., Fitzgerald, K., Rosenblum, K. L., \& Muzik, M. (2018, March). Wearable sensors and machine learning diagnose anxiety and depression in young children. In Proceedings of the 2018 IEEE EMBS International Conference on Biomedical \& Health Informatics (BHI) (pp. 410-413). IEEE. doi:10.1109/BHI.2018.8333455

Ouyang, F., \& Li, X. (2017, October). An vertical handover introduced by adaptive mechanism based on fuzzy analytic hierarchy process for heterogeneous networks. In Proceedings of the 2017 10th International Congress on Image and Signal Processing, BioMedical Engineering and Informatics (CISP-BMEI) (pp. 1-6). IEEE. doi:10.1109/CISP-BMEI.2017.8302160

Ran, W. (2011, May). AHP study on energy indicators system for sustainable development of Henan province. In Proceedings of the 2011 IEEE 3rd International Conference on Communication Software and Networks (pp. 175-179). IEEE. doi:10.1109/ICCSN.2011.6014245

Saaty, T. L. (1980). The analytic hierarchy process. New York, NY: McGraw-Hill.

Sendurur, E. (2018). Students as information consumers: A focus on online decision making process. Education and Information Technologies, 23(6), 3007-3027. doi:10.1007/s10639-018-9756-9

World Health Organization. (2018). WHO Mental Health Gap Action Programme (mhGAP).

Yu, H., Ma, Y., Wang, L., Zhai, Y., \& Du, Z. (2017, August). A method for evaluating the rescue priority level of power line post-disaster based on AHP. In Proceedings of the 2017 IEEE International Conference on Mechatronics and Automation (ICMA) (pp. 35-39). IEEE. doi:10.1109/ICMA.2017.8015784 
Chaymae Benfares is a PhD student at the National School of Applied Sciences, in Ibn Tofail University Kenitra, Morocco. Her research interests are in healthcare, machine learning, data mining and recommander systems.

Ouidad Akhrif is a Ph.D Student and state engineer at the National School of Applied Sciences, in Ibn Tofail University Kenitra, Morocco. Her research interests are smart city and machine learning.

Younès El Bouzekri El Idrissi is a professor at National School of Applied Sciences in Ibn Tofail University Kenitra, Morocco.

Karim Hamid is a Clinical Psychologist at the Center of Oncology and Hematology, Mohammed VI Uni- versity Hospital Center of Marrakech. He has a Doctorate in Psychology from the University Sidi Mohammed Ben Abdellah of FES. He is in charge of the follow-up and psychological management of cancer patients, through psychological diagnosis of psychic disorders. 